Fecha de recepción: septiembre 2019 Fecha de aceptación: noviembre 2019 Versión final: febrero 2020

\section{La diferencia entre diseñar y ejecutar. El diseño en los tiempos del copy-paste}

Martha Gutiérrez Miranda ${ }^{(1)}$

\begin{abstract}
Resumen: El Diseño, como muchas otras disciplinas, responde a las necesidades y exigencias de su tiempo, es un reflejo de la sociedad en la que aparece y se constituye bajo la influencia del contexto social. Su función es impactar directamente a una determinada sociedad y permitir en el desempeño diario, mejorar nuestra adaptación al entorno artificial y la calidad de vida. Como disciplina muy reciente y desde la perspectiva de la formación de profesionales en el área, se ve condicionada por las innovaciones propias del momento histórico que vive la profesión y que influyen en el sistema educativo y sus métodos de enseñanza. Así, este documento, a manera de reflexión, se integra como resultado de un proceso de análisis relativo al papel que están desempeñando las tecnologías en la formación de los diseñadores. Se trata de una aproximación en torno a la forma en que se han modificado y acondicionado los escenarios, formales e informales, que preparan a aquellos que buscan desempañarse en esta área, sean o no, profesionales. Es apenas un esbozo de la responsabilidad que entrañan las escuelas, universidades y demás espacios, sean reales o virtuales, en la definición y promoción de los saberes y destrezas que se supone deben tener un diseñador y el papel que ocupa la tecnología en todo ello.
\end{abstract}

Palabras clave: diseño - formación - tecnología - comunicación.

[Resúmenes en inglés y portugués en la página 115]

(1) Universidad Autónoma de Querétaro. Diseñadora de la Comunicación Gráfica con Maestría en Mercadotecnia, Doctorado en Diseño con Línea Terminal en Nuevas Tecnologías y Posdoctorado en Innovación, Cultura y Tecnología. Profesora-investigadora de Tiempo Completo y Coordinadora de la Maestría en Diseño y Comunicación Hipermedial, UAQ, México. Miembro del Sistema Nacional de Investigadores CONACYT-México.

\title{
Introducción
}

El constante y continuo desarrollo de las nuevas tecnologías arrastra con él a las distintas disciplinas que se ven obligadas a evolucionar a la misma velocidad. El diseño gráfico es una de esas áreas que no se puede resistir al incesante cambio y a la permanente "mejora" 
que ofrece la tecnología, como parte no sólo del proceso creativo y de producción, sino de la formación del profesional del diseño. Sin embargo, algo que se cuestiona y que inclusive sigue siendo un punto de controversia entre un producto hecho por un profesional y uno realizado por un improvisado, reside en la importancia de trabajar con un método, en la formación integral del diseñador, en la concepción de lo que es y no es el diseño y en verdaderamente ofrecer soluciones a partir de un proceso creativo, sistemático y estructurado. Hoy manejar la tecnología parece ser principio y fin, pero y entonces ¿cómo hacerle ver a los clientes la importancia de depositar su confianza en un profesional del diseño y no en alguien que simplemente sepa operar la tecnología?

Así como en la vida existen muchos mitos para explicar fenómenos, sucede de igual manera con disciplinas como el diseño, pues de forma un tanto generalizada, en términos generales no se sabe bien de qué se trata o qué es lo que hace. Aunado a esto, el abaratamiento y proliferación de tecnologías, la presencia de internet con todo lo que ofrece, el acceso a programas de diseño que están a la mano de cualquier persona junto con las soluciones "express" que promueven online o que nulifican al profesional del ramo, han propiciado la aparición de pseudo-diseñadores informales o improvisados, que compran una computadora, recurren a turoriales o que realizan un curso para saber utilizar esos programas o tecnologías y luego se auto-denominan diseñadores.

Pero ¿qué pasaría si alguien pudiera y decidiera convertirse en médico leyendo libros de medicina o mirando videos en youtube? Seguramente todos pensarán que es inconcebible, en cambio con el diseño las personas reaccionan diferente, pues aparentemente es posible diseñar sin estudiar previamente y a nadie parece importarle demasiado.

El problema generalizado radica en la percepción que se tiene sobre la profesión, pues la mayoría de las personas no saben qué es el diseño, lo que ofrece y lo que implica en la vida diaria. Tal vez, porque es tan cotidiano que pasa desapercibido, o simplemente porque nunca se han detenido a pensar que las cosas que utilizamos todos los días (desde la taza para el café, la ropa, los envases y etiquetas de todo lo que comemos, etc.) mayoritariamente, han pasado por un proceso de Diseño.

En una entrevista que realizó el periódico La Nación a Joan Costa en 1987, dónde le preguntaban sobre el diseño y sus funciones, el respondió:

Para algunos, el diseño tiene la mala fama de ser un instrumento cuyo único objetivo es hacer las cosas más bonitas. Este reduccionismo identifica al diseño con la decoración, pero cuando el diseño tiende a la decoración y a la ornamentación pierde parte de su vigor comunicativo. Definitivamente, la estética no es la principal función del diseño, aunque el componente estético siempre forma parte de su mensaje.

En la misma entrevista afirma que un diseñador lo que hace es comunicarse, creando un mensaje para los ojos y para la mente. Y como siempre, concluye diciendo que un mensaje debe tener fundamentalmente en cuenta al destinatario, es decir, al usuario final del diseño. En este sentido, el diseño como práctica inminentemente profesional, no puede ni debe deslindarse del usuario, ni de los procesos inherentes de comunicación en los que 
debe quedar inserto y por supuesto, no debe apartarse de cánones y elementos de fondo, que van mucho más allá de desarrollar algo bonito o utilizar una tecnología novedosa. Con respecto a lo anterior, el mismo diario, en el año 2016 entrevista a Milton Glaser, uno de los grandes referentes del diseño y quizá el diseñador más famoso del mundo, quien afima: "cuando uno empieza a diseñar siempre se pone en el lugar del público. ¿Quiénes son? ¿Qué quieren? ¿Qué podemos mejorar? ¿Cómo atrapar su atención? Uno no empieza pensando en la belleza de un diseño, sino en qué se necesita”.

Es el mismo Glasser, quien al ser invitado por el American Institue of Graphic Arts (AIGA), en un muy revelador discurso afirma sobre lo que el diseño Gráfico es, aseverando:

Prefiero la visión más amplia, que relaciona a nuestra actividad con las necesidades fundamentales de la especie humana: una especie cuya característia distintiva es hacer las cosas con un propósito; lo que resulta ser la descripción justa de lo que hacemos los diseñadores.

A propósito del tema Norberto Cháves, en una conferencia en 2006, que quedó plasmada en las Actas de Diseño de la Universidad de Palermo, comenta:

Ha transcurrido ya casi un siglo desde que se acuñara el término "diseño" para denominar a esa entonces nueva práctica productiva. A lo largo de ese período, el diseño ha ido sufriendo una serie de transformaciones que han incidido en la modificación de su propio concepto. Debido a ese dinamismo de cambio, también se ha ido generando una serie de errores de definición, agravados por los usos abusivos del término "diseño".

En el texto que acompaña su charla también indica que al cabo de varias décadas -relativamente pocas- el diseño se ha transformado en algo muy distinto a aquél de los principios. Hoy día, el diseño invade el consumo masivo y todos los sectores de la industria productiva, la distribución y los servicios e inclusive, como también lo afirma hay un abuso del término diseño, que se ha utilizado como bandera de ese consumismo y que se agrega como calificativo para los productos, lo que lógicamente confunde más los alcances y concepciones del diseño.

En ese sentido, se convive con la idea de que la ropa es "de diseño", los muebles son "de diseño", y apelando a esta adjetivación, pues efectivamente todos los objetos "diseñados" parecen implicar con este mote a lo "moderno", "de última moda" o "novedoso", pero no todos son objetos "de diseño", pues como afirma, esto lo reduciría a una sola manifestación o asociación.

Al igual que lo refiere Norberto, el diseño no es arte, por más que alguno de sus productos estén llenos de él. El diseño no es de ninguna manera una ciencia, aunque puede recurrir a instrumentos científicos. El diseño sólo tiene función social allí donde el respectivo programa se la reclame. Tampoco podemos concebir al diseño como un sistema axiomático autónomo que aplique sus normas a la realidad para configurar los objetos a imagen y semejanza de esos axiomas. El diseño es la fase de un sistema productivo en el que se define la totalidad de las características de un producto, su forma de producción, distribución y uso. 
Este desconocimiento sobre la profesión ha implicado que también proliferen muchas instituciones que ofertan formación, actualización o simples cursos -sobre todo vinculados con tecnologías o bien software "de diseño"- dónde aparentemente forman a estudiantes para "saber diseñar". Y esta condición lo único que ha logrado es que la profesión como tal, vaya perdiendo su valor. Pero no sólo eso, también muchas de las escuelas formales e inclusive de amplia tradición en el Diseño han sucumbido a los encantos de la tecnología y sin mesura cada día le apuestan más a la tecnología, inclusive suprimiendo otras áreas importantes de la formación integral del diseño. Y yendo mucho más lejos, integran o "mejoran" planes y programas de estudio con un alto componente técnico y tecnológico, que a simple vista puede parecer una respuesta a lo que el mercado les demanda de un profesional del diseño, pero si analizamos detenidamente, lo único que están haciendo es poner en riesgo la profesionalización del diseño y la formación profesional.

Parece como si hoy pudiera llamarse diseñador a cualquier que use o maneje una computadora, hace 30 o 40 años, un diseñador era aquél que realmente sabía DISEÑAR. Por lo tanto co-habitar con estos pseudo-profesionales con un nivel cuestionable de conocimientos especializados, pero en ocasiones muy diestros tecnológicamente hablando, es lo que ha causado que el trabajo de diseño haya perdido su valor a través del tiempo.

Aunado a esto, se ha incrementado la desconfianza por parte de los clientes y a menudo se hace difícil que el trabajo sea reconocido y retribuido de forma justa. Entonces, ¿en dónde radica la diferencia? Quizá la pelota vuelve a la cancha de las escuelas, en la formación del diseñador, justamente como un profesional y no como un ejecutante. De lo que se trata es de blindar a nuestra profesión y reducir las filas del copy-paste.

En un artículo que publiqué en Foro Alfa, hace algún tiempo me atrevía a decir que cada vez resulta más extraño pensar en el desarrollo de productos y propuestas sin utilizar la tecnología, incluso para bocetar. De forma generalizada, si un aspirante a diseñador no la utiliza, el resultado puede percibirse como falto de "calidad" e incluso "pobre" de propuesta. Esto lo sigo pensando, pues estamos acostumbrados a relacionar el trabajo del diseño directamente con el uso de la tecnología.

Insisto en que eso no está mal, si consideramos a la tecnología como una herramienta para el desarrollo. El problema no está en el hecho de involucrarla en la producción del diseño, sino cuando se le confiere el carácter de panacea, cuando se piensa en ella como la solución a todos los problemas, o cuando se da por sentado que sin tecnología es imposible concebir un "buen producto".

Buena parte de este malentendido o "mala costumbre", se le puede atribuir a la imagen preconcebida o estereotipada de diseñador modelo, que como clisé se prefigura con una computadora bajo del brazo. Si pudiéramos trasladar la visión de Karl Jung, en torno al arquetipo de un diseñador en el contexto del siglo XXI, en el estricto sentido de "imágenes colectivas", quizá el único común denominador desafortunadamente sería el uso de la computadora, lo que refuerza el hecho de que no es sencillo identificar en el consciente colectivo lo que es o hace un diseñador.

Adicionalmente, en las escuelas y universidades se integran modelos de enseñanza repletos de tecnicismos, neologismos, anglicismos y modismos para referirse al diseño. Y esto no es necesariamente una tragedia, pues finalmente incorporar nuevos enfoques e inclusive extender el lenguaje del diseño siempre lo enriquece, pero cuando se emplean como recurso 
para vender una profesión, no es tan plausible. En este sentido, se aumentan a las ofertas académicas calificativos como digital y multimedia para intentar que los aspirantes crean que nos hemos convertido en centros de vanguardia. Se aderezan propuestas, formales e informales, de carreras y especialidades del Diseño con ornamentos, prefijos y sufijos, sin trasfondo que consiguen su cometido, hacerle creer a los aspirantes que eso es lo que el Diseño es, y aunque suene enredado, en realidad, están muy lejos de la verdad.

Y en los salones de clases, se sigue sobrecargado a los estudiantes con una serie de exigencias en el día a día, que no hacen más que orillarlos a estar prácticamente "pegados" a la computadora, para agilizar las exigencias de la vida escolar y con ello poder darle gusto al profesor, pero realidad no se les enseña a resolver las necesidades de un usuario. Con mayor énfasis se sigue transmitiendo la idea de desarrollar productos y no de concebir, contextualizar y resolver un proyecto, con todas sus implicaciones. Comúnmente se orientan las tareas y esfuerzos con un condicionamiento tipo pavloviano, para cubrir las expectativas de un programa académico y cuesta mucho trabajo relacionar la teoría con la práctica y buscar que se enfrenten a situaciones reales, donde verdaderamente resuelvan necesidades reales.

Con el advenimiento de la tecnología, los docentes mismos no somos capaces de preparar una asignatura o conducir una sesión sin el uso de la tecnología, son pocos o cada vez menos los profesores que prescinden de ellas y apuestan por la práctica directa tipo taller o bien que predican con el ejemplo, que le enseñan a sus alumnos sus procesos de diseño, que transmiten el valor de la teoría a través de su propia práctica o viceversa, que con su práctica profesional demuestran la importancia del proceso, de la teoría y la metodología. Los estudiantes se están acostumbrando a mecanizar el proceso de diseño y en muchas ocasiones les resulta imposible proyectar sin usar la tecnología, particularmente, la informática. Es increíble como en las aulas son incapaces de tomar nota pues lo que se escribe en el pizarrón o se proyecta en la pantalla ahora lo capturan en una imagen y es todavía más raro verlos con un cuaderno de apuntes o bien una bitácora que documente sus procesos. Les resulta imposible pensar con autonomía o reflexionar sobre un tema o idea sin consultar sus celulares o recurrir a lo que se diga en la red; o bien, para iniciar un proceso creativo no llevan a cabo formalmente una investigación, sólo se conforman con hacer una búsqueda en internet y generalmente se quedan con lo primero que el navegador les ofrece sin espíritu selectivo, ni mucho menos crítico.

Y pensando en las demandas actuales, la formación universitaria es un eslabón importante en la cadena de la producción gráfica porque en gran medida depende de ella, pues es la que permite que existan diseñadores, formados con todos los requisitos profesionales de manera que pueden responder a las necesidades, demandas y exigencias del mercado, sin embargo se ha malentendido la incorporación de la tecnología como estrategia para mejorar el propio proceso del diseño.

En general, en las escuelas de diseño el interés se centra en la "forma" o resultado final de los objetos o productos gráficos. Se ha olvidado que la clave para que el diseñador sea verdaderamente un profesional consiste en entender que su papel es producir significados, entendiendo éstos como fenómenos culturales. Cada día cuesta más asimilar que como profesionales, sólo inmersos en la realidad cultural se puede interpretarla y representarla. 
No se puede crear sin conocer, profundizar y convivir. Por eso es que se debe ir más allá para que la "solución" no se reduzca a un simples efectos visuales.

Para centrarnos nuevamente en la situación medular, relativa a la enseñanza del diseño, se puede afirmar que es imposible crear, diseñar o formular una propuesta congruente con el conjunto de problemas de comunicación que la sociedad plantea, si seguimos pensando como entes aislados. La única manera es entender que formamos parte de un tiempo-espacio, que compartimos conocimientos y aptitudes; que la forma como sentimos y percibimos el mundo que nos rodea ha sido asimilada poco a poco de nuestro contexto cultural que es el de la sociedad a la cual pertenecemos. Los objetos y mensajes que se generan desde el diseño verdadero deben ser productos de nuestra cultura, ya que está presente tanto para percibir, como para interpretar y representar al mundo.

Es nuevamente Joan Costa (2014) quien al referirse a los nuevos paradigmas en el ámbito del diseño y la comunicación visual afirma categóricamente:

Debemos centrarnos en el hecho de que el diseño establece un sistema de relaciones constantes entre nosotros y los ambientes que ocupamos, los objetos que utilizamos y los mensajes que integramos. Y así, los productos del diseño forman parte de nuestra cultura (p. 89).

En este orden de ideas, el diseño se constituye como una actividad mediadora que permite configurar el entorno artificial, asimilándose como un elemento significativo que regula las interacciones de los individuos en la sociedad y con la sociedad. Y en la medida que su fin último sea mejorar nuestro hábitat, resolver problemas y en general, mejorar la calidad de vida, la esencia del diseño cumple una función informativa y comunicativa, y de esta forma se constatan elementos distinguibles y evidentes, como la intencionalidad y la significación. Lo que define a los mensajes elaborados a partir del diseño como "constructos humanos y productos culturales".

Este documento, no pretende en forma alguna desmerecer o minimizar la importancia de la tecnología en la formación y práctica profesional del diseño, por el contrario, soy partidaria de su uso, como parte del momento histórico que está viviendo el proceso de formación de los diseñadores, como herramienta de auxilio a la producción, como una aliada para el trabajo y recurso para hacer más eficiente el proceso, no como fin, ni como medio per se.

Por lo tanto, se sigue insistiendo en que como formadores, cuidemos al menos los procesos propios de maduración de un profesional de la comunicación visual, pues en el camino, insistimos en introducirlos a ese mundo tecno-informático muy prematuramente y se están volviendo adictos a las soluciones express que quizá a primera vista parecen impactantes, pero que en el fondo no conllevan siquiera un proceso mínimo de conceptualización y estructura.

Con conocimiento de causa y luego de mucho reflexionar se sigue creyendo que se nos ha hecho fácil atrapar la enseñanza del diseño en un modelo que poco se despega del antiguo, viejo y obsoleto conductismo, donde en realidad continua coartándose y limitándose la creatividad, y el principal verdugo "no se ha quitado el disfraz de manzana y sigue refugiado en su casa de adobes". 


\section{Reflexiones finales}

Si el diseñador se concibe como un comunicador, debe comprender a la comunicación como un fenómeno cultural por excelencia, como un universo de signos y códigos que son los elementos constitutivos de la colectividad. Bruno Munari (1972), a propósito de la revisión y la segunda edición de su texto Diseño y Comunicación Visual, señala atinadamente que ante los nuevos problemas que se presentan en torno a la forma de enseñar, deben asumirse nuevos instrumentos y nuevas formas de abordarla. Refiere que en las clases se sigue enseñando un pasado más o menos remoto, intentando seguir apegados a una tradición "cómoda", sin complicaciones y sin demasiada inversión de tiempo, lo que hace que los estudiantes pronto se den cuenta de que la realidad fuera de la escuela es muy distinta y cuándo logran hacer consciente esto y deshacerse de las formas en que aprendieron ciertos conocimientos y técnicas, se vuelven aprendices autodidactas y llegan a la conclusión de que la escuela es demasiado vieja o bien de que lo inmediato es lo que se privilegia.

Esta condición y práctica, que él ya señalaba en la década de los 70’s hoy está más que popularizada, justamente con las facilidades que otorgan las tecnologías para aprender de forma casi instantánea, situación que nos devuelve a una pregunta provocadora que se lee en el mismo texto "¿Para qué sirve una escuela si no es para preparar individuos capaces de enfrentarse con el mundo futuro? Y estas técnicas no tienen nada que ver con operar una máquina, especializarse en ejecutar soluciones, digitalizar los procesos o "tecnologizar" ${ }^{\prime}$ a la disciplina. Se trata en definitiva de descontextualizar al diseño como práctica productiva profesional de la mano exclusivamente de las tecnologías y recontextualizarlo de tal manera en que estas tecnología sumen habilidades o competencias, en el sentido estricto de requisitos para abonar al profesional del ramo. Es decir, no se trata de mecanizar el proceso o automatizar las soluciones, por definir conceptualmente a las prácticas que vemos todos los días en miles y miles de páginas que por unos cuantos pesos ofrecen un "hágalo usted mismo" y diseñe su logotipo en 5 pasos o al más puro "american style", en el que se pueden descargar plantillas prefabricadas adaptables mágicamente a cualquier necesidad de diseño.

El momento actual se distingue por la acelerada transformación en todos los campos del conocimiento y del quehacer humano. También se distingue por la desinformación, o la sobrecarga de información que termina sin hacerle sentido al estudiante, que carente de procesos de pensamiento más estructurados y maduros, como el análisis y síntesis profundos, recurren a mecanismos para discriminar o seleccionar la información recurriendo simplemente a copiar y pegar, sin siquiera analizar.

Esto provoca que los productos de comunicación que se generan, a veces sean simples imitaciones, burdas copias o descarados plagios y que a simple vista se note la total ausencia de reflexión, investigación, conceptualización, trabajo, esfuerzo y de una actitud crítica indispensable. El estudiante se está acostumbrando a asumir acciones, ideas y formas que no responden a su cultura, sino a culturas diferentes. La falta de autenticidad de esas soluciones que está proponiendo no se deben tanto al origen externo de esas ideas, sino al hecho de ser repetidas sin reflexión ni crítica. Estamos fomentando una cultura de la imitación y como afirma Villoro(1965): "La cultura imitativa no es inauténtica por dejarse 
influir por elementos externos a la 'realidad', sino por aceptarlos sin ponerlos en cuestión integrándolos a nuestros deseos y necesidades reales".

Hoy que tan en boga está el término innovación, se debe repensar desde la formación de los diseñadores, todas sus implicaciones, porque resulta inconsciente, inconsistente e irresponsable, considerar que solo la tecnología le otorga esa condición a nuestra profesión. En efecto en los avisos de ocasión, en las ofertas de trabajo y todo aquél espacio dónde se busca un diseñador, el perfil no describe a un profesional, sino enuncia a manera de check-lista, una cantidad de aplicaciones y programas que debe manejar y quizás las habilidades más destacables que debe comportar. Esta situación puede abatir y deprimir a cualquiera, pero no es el objetivo de esta reflexión. Por el contrario, se busca poner de manifiesto el compromiso que debe asumirse en las aulas y en la formación integral de los diseñadores y la importancia, como ya se mencionó arriba, de blindar nuestra profesión. Ojalá esta preocupación que se expone como especie de catarsis personal y con la que quizá más de uno simpatiza, revierta esos nuevos estilos de concebir la enseñanza y modelar a las escuelas, por lo menos a las responsables de formar diseñadores, donde paradójicamente cada vez hay más equipos de cómputo, que libros y dónde se enseña a usar la tecnología, antes que utilizar la razón.

\section{Notas}

1. Ofrezco una disculpa porque tecnologizar no es un verbo aceptado por la RAE, sin embargo en esta ola de sucumbir ante los neologismos o barbarismo de la modernidad, se emplea aquí para hacer alusión al infinitivo simple que se refiere a incorporar las tecnologías en un proceso o ambiente tradicional.

\section{Referencias bibliográficas}

Costa, J. (1987). Imagen Global, Enciclopedia del diseño, España: Ediciones CEAC. Diario La Nación, 1 de junio de 2008 , Entrevista de Carlos Guyot a Joan Costa. Disponible en: https://www.lanacion.com.ar/opinion/joan-costa-el-diseno-socializa-el-conocimientonid1017188

(2014). Diseño y Comunicación Visual: el nuevo paradigma, Revista Expertia, Vol. 2, No. 4

El país semanal. Entrevista de Anatxu Zablabeascoa: Milton Glaser: "Diseño y Arte son asuntos distantes", 19 de Julio de 2016, Disponible en https://elpais.com/elpais/2016/07/20/ eps/1468965934_146896.html

Gutiérrez, M. (2013). Mucha Tecnología y poco diseño, Foro Alfa, Disponible en https:// foroalfa.org/articulos/mucha-tecnologia-y-poco-diseno, Publicado 08/04/2013

Munari, B. (1972). Diseño y Comunicación Visual, 2da. Edición, España: Gustavo Gili.

Soto M. y Meléndez M. (2008). El diseño: Del oficio a la profesión, Actas de Diseño No4 Año II, Vol. 4, Buenos Aires, Argentina. 
Villoro, L. (1965-1966). "Historia de las ideas", Historia Mexicana, vol. XV, núms. 58-59, México:El Colegio de México, Disponible en https://www.jstor.org/stable/25134577?readnow=1\&seq=1\#page_scan_tab_contents

\begin{abstract}
Design, like many other disciplines, responds to the needs and demands of its time, reflects the society in which it appears and is constituted under the influence of the social context. Its function is to directly impact a given society and allow daily performance, improve our adaptation to the artificial environment and the quality of life. As a very recent discipline and from the perspective of the training of professionals in the area, it is conditioned by the innovations of the historical moment that the profession lives and that influence the educational system and its teaching methods. Thus, this document, by way of reflection, is integrated as a result of an analysis process related to the role that technologies are playing in the training of designers. It is an approximation around the way in which the formal and informal scenarios have been modified and conditioned, which prepare those who seek to get involved in this area, whether or not they are professionals. It is just an outline of the responsibility involved in schools, universities and other spaces, whether real or virtual, in the definition and promotion of the knowledge and skills that a designer is supposed to have and the role that technology occupies in all this.
\end{abstract}

Keywords: design - training - technology - communication.

Resumo: $\mathrm{O}$ design, como muitas outras disciplinas, responde às necessidades e demandas de seu tempo, é um reflexo da sociedade em que aparece e é constituído sob a influência do contexto social. Sua função é impactar diretamente uma determinada sociedade e permitir o desempenho diário, melhorar nossa adaptação ao ambiente artificial e à qualidade de vida. Por ser uma disciplina muito recente e na perspectiva da formação de profissionais da área, é condicionada pelas inovações do momento histórico em que a profissão vive e que influenciam o sistema educacional e seus métodos de ensino. Assim, este documento, a título de reflexão, é integrado como resultado de um processo de análise relacionado ao papel que as tecnologias estão desempenhando no treinamento de designers. Trata-se de uma aproximação sobre a forma como os cenários formais e informais foram modificados e condicionados, o que prepara aqueles que buscam se envolver nessa área, sejam eles profissionais ou não. É apenas um esboço da responsabilidade envolvida nas escolas, universidades e outros espaços, reais ou virtuais, na definição e promoção do conhecimento e das habilidades que um designer deve ter e do papel que a tecnologia ocupa em tudo isso.

Palavras chave: design - treinamento - tecnologia - comunicação.

[Las traducciones de los abstracts fueron supervisadas por el autor de cada artículo] 